\title{
The hepatic architecture of the coelacanth differs from that of the lungfish in portal triad formation
}

\author{
By \\ Nobuyoshi SHIOJIRI ${ }^{1}$, Sho TANAKA ${ }^{2}$, Hayato KAWAKAMI ${ }^{3,4}$ \\ ${ }^{1}$ Department of Biology, Faculty of Science, Shizuoka University, \\ 836 Oya, Suruga-ku, Shizuoka City, Shizuoka 422-8529, Japan \\ ${ }^{2}$ Department of Marine Biology, School of Marine Science and Technology, Tokai University, \\ 3-20-1 Orido, Shimizu-ku, Shizuoka 424-8610, Japan \\ ${ }^{3}$ Laboratory for Electron Microscopy and ${ }^{4}$ Department of Anatomy, Kyorin University School of Medicine, \\ 6-20-2 Shinkawa, Mitaka-shi, Tokyo 181-8611, Japan
}

-Received for Publication, December 5, 2018 -

Key Words: portal triad, bile ducts, coelacanth, tetrapod, evolution

\begin{abstract}
Summary: The liver architecture of vertebrates can be classified into two types, the portal triad type (having periportal bile ducts) and the non-portal triad type (having non-periportal bile ducts). The former is detectable in the tetrapod liver whereas the lungfish liver has the latter. It remains to be revealed which type of hepatic architecture the coelacanth, which together with the lungfish belongs to the Sarcopterygii, possesses. The present study was undertaken to determine the histological characteristics of the coelacanth liver, and to compare with those of other vertebrates. The coelacanth liver had periportal bile ducts and ductules as detected in mammalian livers. The hepatic artery was found around large portal veins. Hagfish, shark, bichir, sturgeon, bowfin and frog livers had periportal bile ducts and bile ductules, whereas most intrahepatic bile ducts of the lungfish were independent of the distribution of the portal veins as seen in the Otocephala and Euteleostei. The lungfish liver developed duct and ductule structures in the parenchyma. These data indicate that the coelacanth liver had a mammalian-type hepatic architecture with a portal triad, and that the ancestors of tetrapods may have had a portal triad-type liver architecture.
\end{abstract}

\section{Introduction}

The mammalian liver is composed of polyhedral lobule structures, in which hepatic cords are distributed radially along hepatic sinusoids from the central to peripheral regions. The portal triad consisting of the portal vein, hepatic artery and intrahepatic bile duct is formed in the periphery of the lobule. This mammalian type of hepatic architecture is detectable in many vertebrates, including the agnatha, cartilageous fishes, amphibians, reptiles, birds, and actinopterygians before the Elopomorpha ${ }^{1-4)}$. Surprisingly the hepatic architecture of the lungfish, which shares its origin with amphibians, resembles that of the Actinopterygii after the Elopomorpha rather than that of amphibians in terms of intrahepatic bile duct distribution $^{4-7)}$. The biological meaning of this is unknown at present. The hepatic architecture of the coelacanth, which together with the lungfish belongs to the Sarcopterygii, but is an endangered species, has not been examined yet for portal triad formation. Millot et al. $(1978)^{8)}$ reported on its lobulation in young specimens and hematopoiesis near the hepatic capsule. Thus, the hepatic architecture of the coelacanth is worth examining in terms of evolution of hepatic architecture in tetrapods. The results of this study might provide insights into why or how the convergent evolution of the hepatic architecture in the lungfish and fishes after the Elopomorpha occurred.

In the present study, we histochemically examined the histological structure of the coelacanth liver, and compared it with those of other vertebrates. Our results indicate that the coelacanth liver had a mammalian-type architecture, although its fine architecture was not well preserved due to inappropriate fixation and/or long storage of the sample. 


\section{Materials and Methods}

\section{Materials}

Liver pieces of the coelacanth (Latimeria chalumnae) were generously donated from Numazu Deepsea Aquarium \& Coelacanth Museum (Numazu, Japan). Although the precise conditions for fixation and long storage were unknown, the donated sample was believed to have been immersed in $10 \%$ formalin. Liver samples of hagfish, sharks, lungfish, western clawed frog, and fish of the Actinopterygii, which were fixed in a cold mixture of $95 \%$ ethanol and acetic acid (99:1 v/v) or 10\% formalin, were examined as references for hepatic architecture (Table 1). All experiments were carried out in compliance with the "Guide for Care and Use of Laboratory Animals" of Shizuoka University.

\section{Histology}

Tissues were embedded in paraffin after dehydration in alcohol series. Dewaxed sections were stained with hematoxylin-eosin (H-E) and periodic acid-Schiff-hematoxylin (PAS-H). Collagen distribution was visualized with Picrosirius staining ${ }^{9}$. The presence of hemosiderin pigment was assessed by Berlin blue staining. Sudan Black B staining was carried out to demonstrate fat accumulation in frozen sections of the coelacanth liver.

\section{Cytokeratin immunohistochemistry}

When a peroxidase-labeled secondary antibody was used, endogenous peroxidase activity in dewaxed sections was blocked by treatment with phosphate-buffered saline (PBS) containing 3\% $\mathrm{H}_{2} \mathrm{O}_{2}$ for 10 min before incubation with the primary antibody. Dewaxed sections were incubated for $2 \mathrm{hr}$ at room temperature with a rabbit anti-calf keratin antibody (Dako, Carpinteria, CA, USA) at 1/300 dilution in PBS containing $1 \%$ bovine serum albumin (BSA). After thorough washing with PBS, sections were incubated with a Cy3- or peroxidase-labeled donkey anti-rabbit IgG antibody (Jackson ImmunoResearch Lab., West Grove, PA, USA) (1/500 dilution for the Cy3-labeled antibody and 1/200 dilution for the peroxidase-labeled antibody) for $1 \mathrm{hr}$ at room temperature. After thorough washing, sections were mounted in buffered glycerol containing p-phenylenediamine for immunofluorescence. For the immunoperoxidase method, after washing, sections were stained with 3, 3'-diaminobenzidine (DAB), and then with hematoxylin. Control incubations were carried out in PBS containing 1\% BSA instead of the primary antibody.

\section{Electron microscopy}

Liver tissues of the coelacanth were again fixed in $2.5 \%$ glutaraldehyde in phosphate buffer ( $\mathrm{pH}$ 7.2) overnight on ice. After washing, the tissues were fixed in $1 \% \mathrm{OsO}_{4}$ for $1 \mathrm{hr}$ on ice. Tissue specimens were ordinarily processed for transmission electron microscopical observation
(JEM-1011; JEOL, Akishima, Japan).

\section{Results}

\section{Histology of the coelacanth liver}

The coelacanth liver lobe examined was dark brownish and thick $(15 \times 20 \mathrm{~cm} ; 1.5 \mathrm{~cm}$ in thickness $)$, and floated in a formalin fixative with large amounts of oil droplets that were derived from the liver sample itself. The histology of the liver tissue in H-E-stained preparations was not well preserved, possibly due to inappropriate fixation and too long immersion in formalin solution without renewal. Most nuclei of hepatocytes appeared to be lost (Fig. 1A-C), although some nuclei of nonparenchymal cells such as biliary cells and capsule cells were present (Fig. 1D, H). The cytoplasm of hepatocytes contained scanty spaces, and stored fatty substances, which were positive for Sudan Black B staining (Fig. 2A). Berlin blue staining also demonstrated that hepatocytes accumulated hemosiderin pigments (Fig. 2B). Melanomacrophages were scattered in the liver parenchyma (Fig. 1A, B). Several large vessels having abundant connective tissue were noted in some places. Sirius red staining demonstrated that the vessels had abundant collagen fibril or fiber deposition (Fig. 3A, B). In the connective tissue, bile ductlike structures, which were composed of epithelial cells, were observed (Fig. 1C, D). The epithelial cells were apt to disperse into single cells, possibly due to inappropriate fixation. They were positively immunostained with the anti-calf keratin antibody, although the background staining was comparatively high (Fig. 1E). However, the thick connective tissue layer was negatively immunostained. The antibody also detected ductular structures around vessels (Fig. 1F). The thick portal connective tissue contained several spaces without epithelial-like cells, and might have been a hepatic artery, suggesting that the coelacanth liver had a portal triad. The liver tissue was covered with adipose tissue or a capsule layer (Fig. 1G, H). Hematopoiesis was not observed near the capsule layer.

Transmission electron microscopical analyses confirmed that the ultrastructure of hepatocytes was not well preserved (Fig. 4A), and that the melanomacrophages abundantly seen in the liver contained many melanosomes (Fig. 4B).

\section{Histology of other vertebrate livers}

For reference, the livers of various vertebrates, including hagfish, shark, lungfish, frog, bichir, sturgeon, bowfin, spotted gar, silver arowana, Japanese eel, goldfish and thread-sail filefish, were histologically examined. The hagfish, shark, bichir, sturgeon, bowfin, spotted gar and silver arowana livers had periportal bile ducts, whereas most intrahepatic bile ducts of the lungfish examined (four species) were independent of the distribution of the portal vein as seen in most Actinopterygii after the Elopomorpha 
Table 1. Liver samples of various vertebrates used in the present study

\begin{tabular}{|c|c|c|c|c|}
\hline Taxonomy & & English name & Scientific name & Sample description \\
\hline \multicolumn{5}{|l|}{ Agnatha } \\
\hline \multicolumn{5}{|l|}{ Myxini } \\
\hline \multicolumn{5}{|c|}{ Myxiniformes } \\
\hline & & Hagfish & Eptatretus burgeri & 3 males; 3 females (Suruga Bay) \\
\hline \multicolumn{5}{|l|}{ Gnathostomata } \\
\hline \multicolumn{5}{|l|}{ Chondrichthyes } \\
\hline \multicolumn{5}{|l|}{ Holocephali } \\
\hline & Chimaeriformes & & & \\
\hline & & Silver chimaera & Chimaera phantasma & 1 sample (male; Suruga Bay) \\
\hline \multicolumn{5}{|l|}{ Elasmobranchii } \\
\hline \multicolumn{5}{|l|}{ Neoselachii } \\
\hline \multicolumn{5}{|l|}{ Selachii } \\
\hline \multicolumn{5}{|c|}{ Galeomorphii } \\
\hline \multicolumn{5}{|c|}{ Heterodontiformes } \\
\hline & & Japanese bullhead shark & Heterodontus japonicus & 2 samples (1 male, 1 female; Sagami Bay) \\
\hline \multicolumn{5}{|c|}{ Squalomorphi } \\
\hline \multicolumn{5}{|c|}{ Hexanchiformes } \\
\hline & & Frilled shark & Chlamydoselachus anguineus & 1 sample (Suruga Bay) \\
\hline \multicolumn{5}{|l|}{ Sarcopterygii } \\
\hline \multicolumn{5}{|l|}{ Coelacanthimorpha } \\
\hline \multicolumn{5}{|c|}{ Coelacanthiformes } \\
\hline & & Coelacanth & Latimeria chalumnae & $\begin{array}{l}1 \text { sample (a kind donation from Numazu } \\
\text { Deepsea Aquarium \& Coelacanth Museum) }\end{array}$ \\
\hline Dipnoi & & & & \\
\hline & Lepidosireniformes & & & \\
\hline & & African lungfish & Protopterus annectens & 2 samples ( $50 \mathrm{~cm}, 20 \mathrm{~cm}$; local distributor) \\
\hline & & African lungfish & Protopterus droi & 2 samples (females, $15 \mathrm{~cm}$; local distributor) \\
\hline & & African lungfish & Protopterus aethiopicus & 1 sample ( $15 \mathrm{~cm}$; local distributor $)$ \\
\hline & & South American lungfish & Lepidosiren paradoxa & 2 samples ( $15 \mathrm{~cm}$; local distributor $)$ \\
\hline Actinopterygii & & & & \\
\hline Branchiopterygii & & & & \\
\hline & Polypteriformes & & & \\
\hline & & Bichir & Polypterus endlicheri endlicheri & 2 samples ( $20 \mathrm{~cm}$; local distributor) \\
\hline Chondrostei & & & & \\
\hline & Acipenseriformes & & & \\
\hline & & Sterlet & Acipenser ruthenus & 1 sample (15 cm; local distributor) \\
\hline Neopterygii & & & & \\
\hline & Lepisosteiformes & & & \\
\hline & & Spotted gar & Lepisosteus oculatus & 1 sample (female, $45 \mathrm{~cm}$; local distributor) \\
\hline & Amiiformes & & & \\
\hline & & Bowfin & Amia calva & 2 samples (10 cm; local distributor) \\
\hline Teleostei & & & & \\
\hline Osteoglossomor & & & & \\
\hline & Osteoglossiformes & & & \\
\hline & & Silver arowana & Osteoglossum bicirrhosum & 2 samples (15 cm; local distributor) \\
\hline Elopomorpha & & & & \\
\hline & Anguilliformes & & & \\
\hline & & Japanese eel & Anguilla japonica & 5 samples (local distributor) \\
\hline Otocephala & & & & \\
\hline Ostariophy & & & & \\
\hline & Cypriniformes & & & \\
\hline & & Goldfish & Carassius auratus auratus & 3 samples ( 1 male, 2 females; local distributor) \\
\hline Euteleostei & & & & \\
\hline Acanthopt & rygii & & & \\
\hline Perc & morpha & & & \\
\hline & Tetraodontiformes & & & \\
\hline & & Thread-sail filefish & Stephanolepis cirrhifer & 3 samples (Sagami Bay) \\
\hline Amphibia & & & & \\
\hline Lissamphibia & & & & \\
\hline & Anura & & & \\
\hline & & Western clawed frog & Xenopus tropicalis & 2 males; 2 females \\
\hline
\end{tabular}



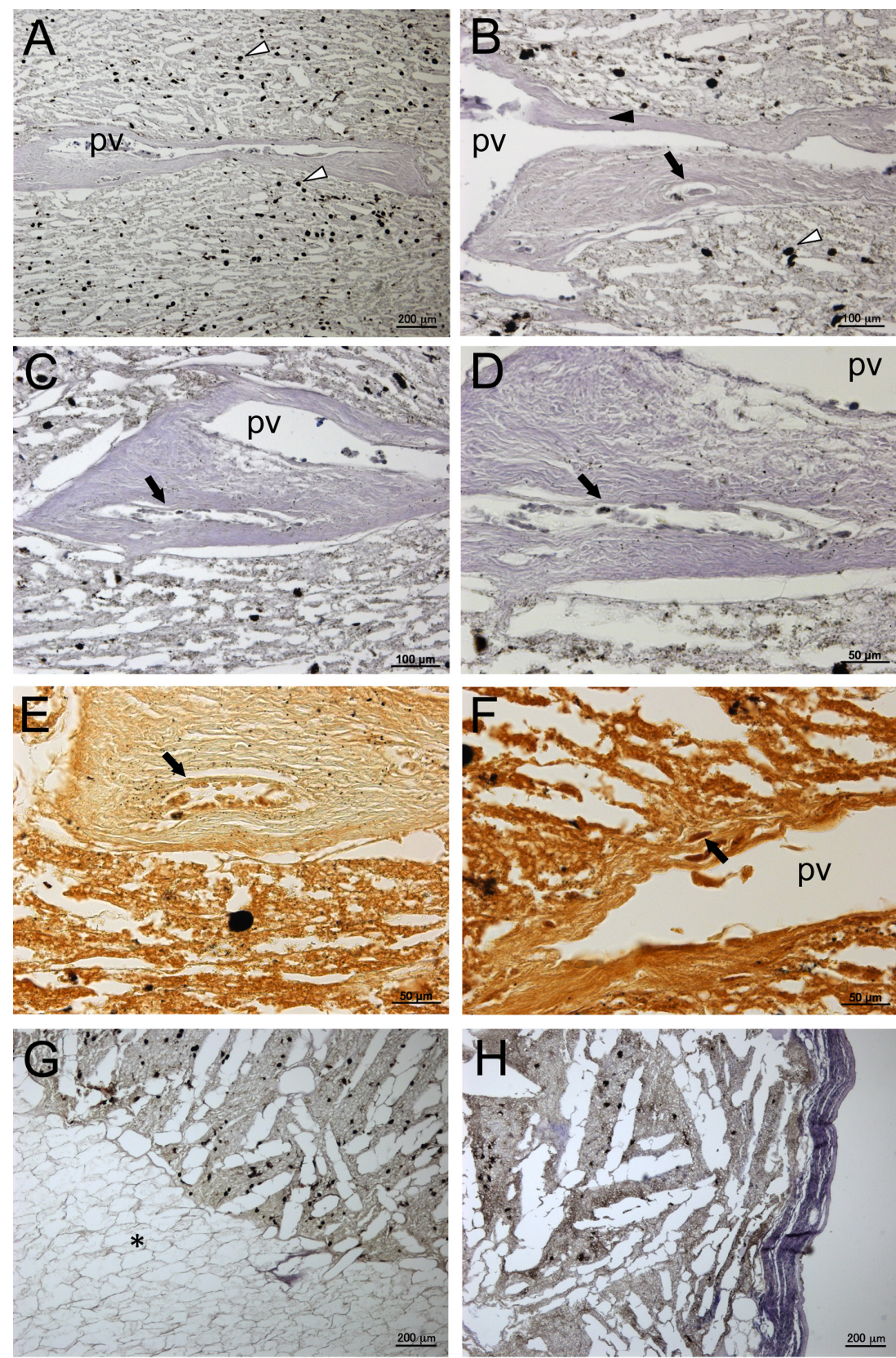

Fig. 1. Histology of the coelacanth liver. (A-D, G, H) H-E staining. (E, F) Cytokeratin immunohistochemistry. A large blood vessel surrounded by abundant connective tissue is observed (A). Scattered melanomacrophages are visible (white arrowheads). The large blood vessel possesses an intrahepatic bile duct (arrow) and artery (black arrowhead), and is concluded to be a portal vein (B). Epithelial cells of intrahepatic bile ducts, each of which is disaggregated, are observed in the connective tissue of the portal vein (arrow, C, D). Epithelial cells of intrahepatic bile ducts around the portal vein are positively immunostained for cytokeratin (arrow, E). Ductular cells showing strongly positive cytokeratin immunostaining are noted around a smaller portal vein (arrow, F). The coelacanth liver was covered with adipose tissue (asterisk in G) or a Glissonian capsule $(\mathrm{H})$. pv, portal vein.
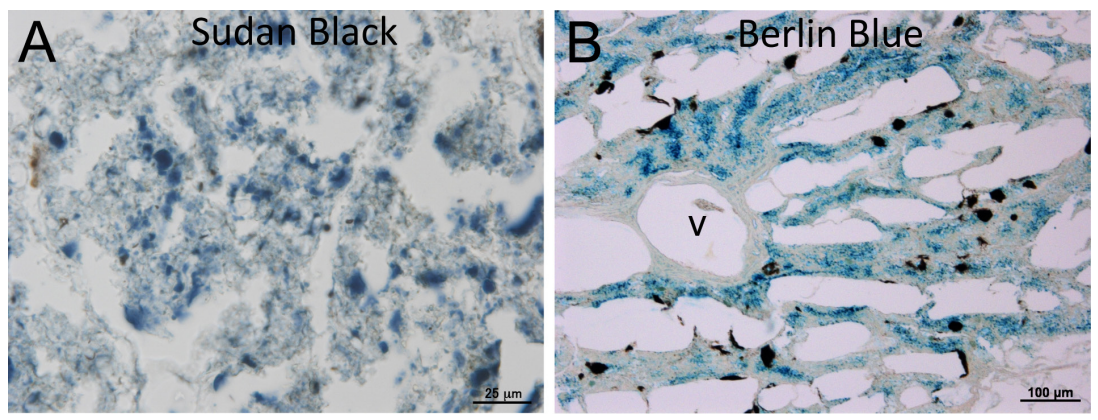

Fig. 2. Fat and hemosiderin accumulation of the coelacanth liver. (A) Sudan black B staining. (B) Berlin blue staining. Hepatocytes accumulate fat (A) and show hemosiderin reaction (B). v, vessel. 

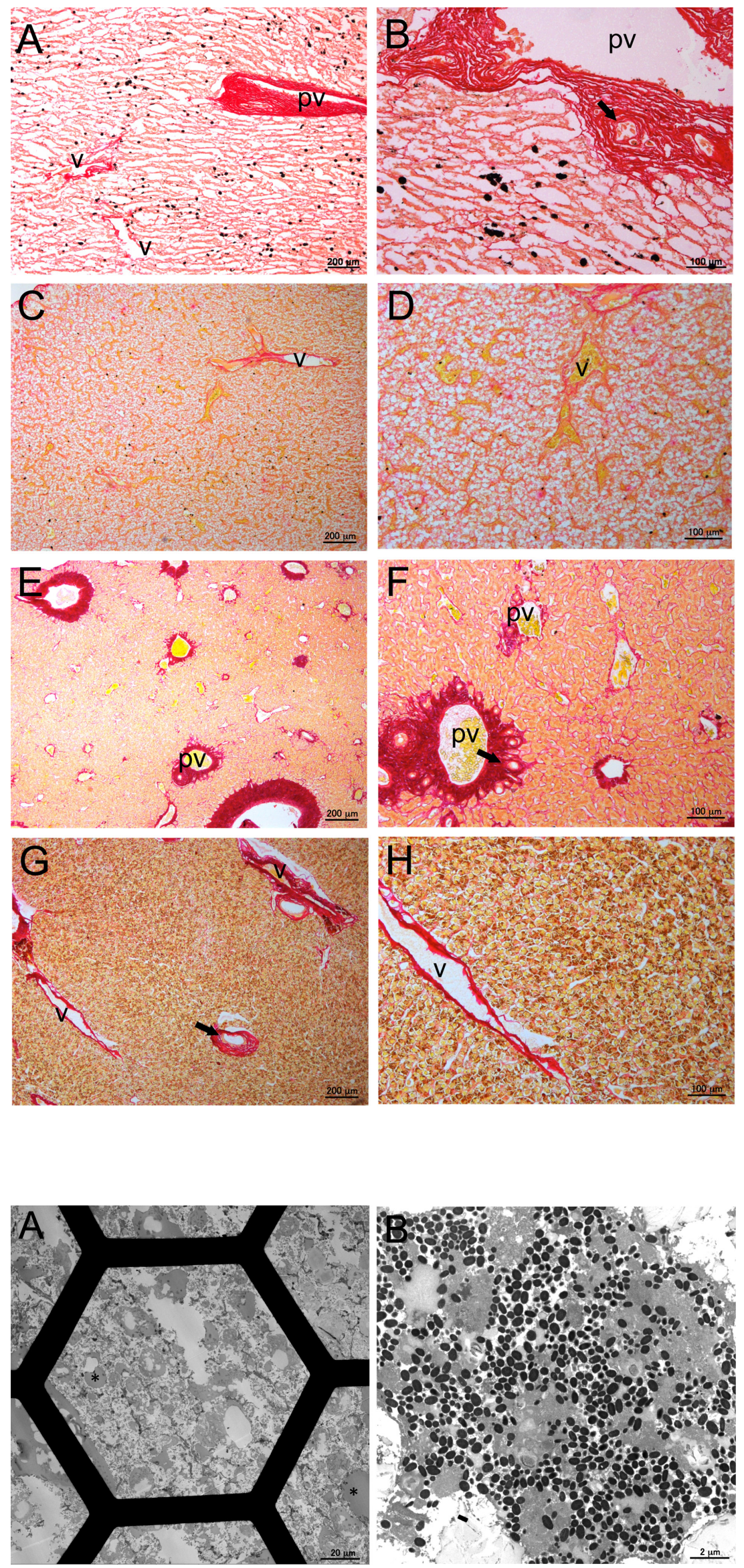

Fig. 4 the coelacanth liver. (A) Liver parenchyma. (B) Melanomacrophage. The liver parenchyma does not show good ultrastructural preservation (A). Lipid droplets (asterisks) are abundant. The melanomacrophage has many melanosomes (B). 
(Figs. 5, 6). The Japanese eel had periportal intrahepatic bile ducts, which also entered the liver parenchyma independent of portal veins. In vertebrate livers with periportal bile ducts, periportal arteries were also noted ("portal triad"). Immunohistochemical analyses of cytokeratin ex- pression also demonstrated that the hagfish and frog livers had periportal bile ducts whereas the lungfish and threadsail filefish, which is one of the Euteleostei, had isolated bile ducts independently developing in the liver parenchyma (Fig. 7). Melanomacrophages were distributed in
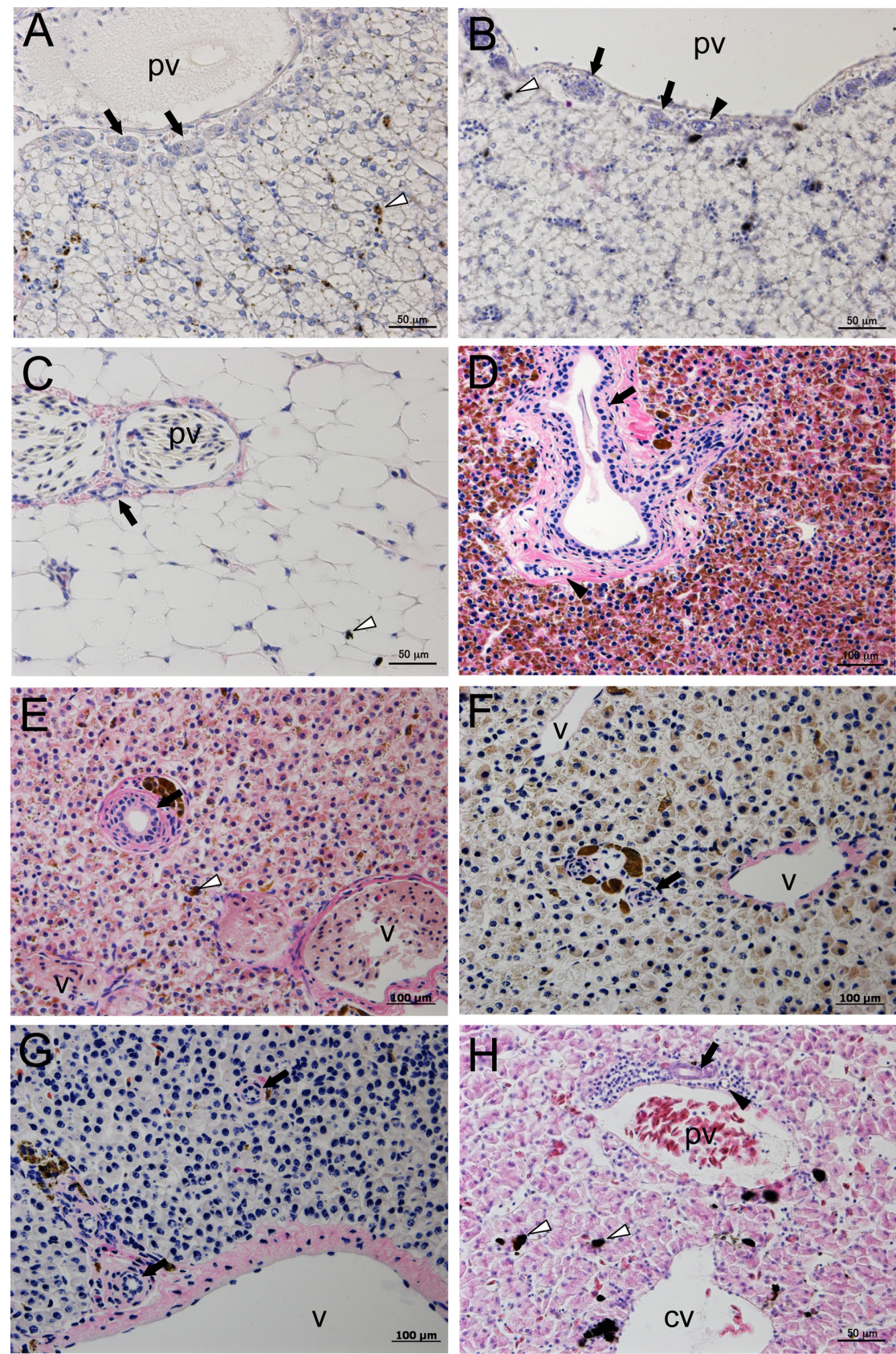

Fig. 5. Intrahepatic bile duct distribution in livers of various vertebrates. (A) Hagfish. (B) Silver chimaera. (C) Frilled shark. (D) African lungfish (Protopterus annectens). (E) Marbled lungfish (Protopterus aethiopics). (F) Spotted African lungfish (Protopterus dolloi). (G) South American lungfish (Protopterus lepidosiren). (H) Xenopus tropicalis. H-E staining. Intrahepatic bile ducts or ductules are developed around portal veins in livers of the hagfish, silver chimaera, frilled shark and $X$. tropicalis (arrows, A-C, H). The histology of the frilled shark liver closely resembles that of the adipose tissue well (C). In the lungfish livers, intrahepatic bile ducts do not always run along blood vessels (arrows, D-E). Either intrahepatic bile ducts around blood vessels or developing in the parenchyma are observed (G). Black arrowheads indicate the hepatic artery. White arrowheads indicate melanomacrophages. cv, central vein; pv, portal vein, v, vessel. 
the livers of shark, frog, bichir and arowana (Fig. 5A-C, E, H; Fig. 6A-E). Collagen deposition demonstrated with Sirius red staining was detectable in the connective tissue around large blood vessels (Fig. 3C-H). Heavy collagen deposition was noted in those of the bichir liver, just like the coelacanth liver (Fig. 3A, B, E, F). The Glissonian capsules varied among the animals examined (Fig. 8). The capsules covering the hagfish, shark, bichir and lungfish livers were thick compared with those of mammalian livers. The bichir liver was also covered with
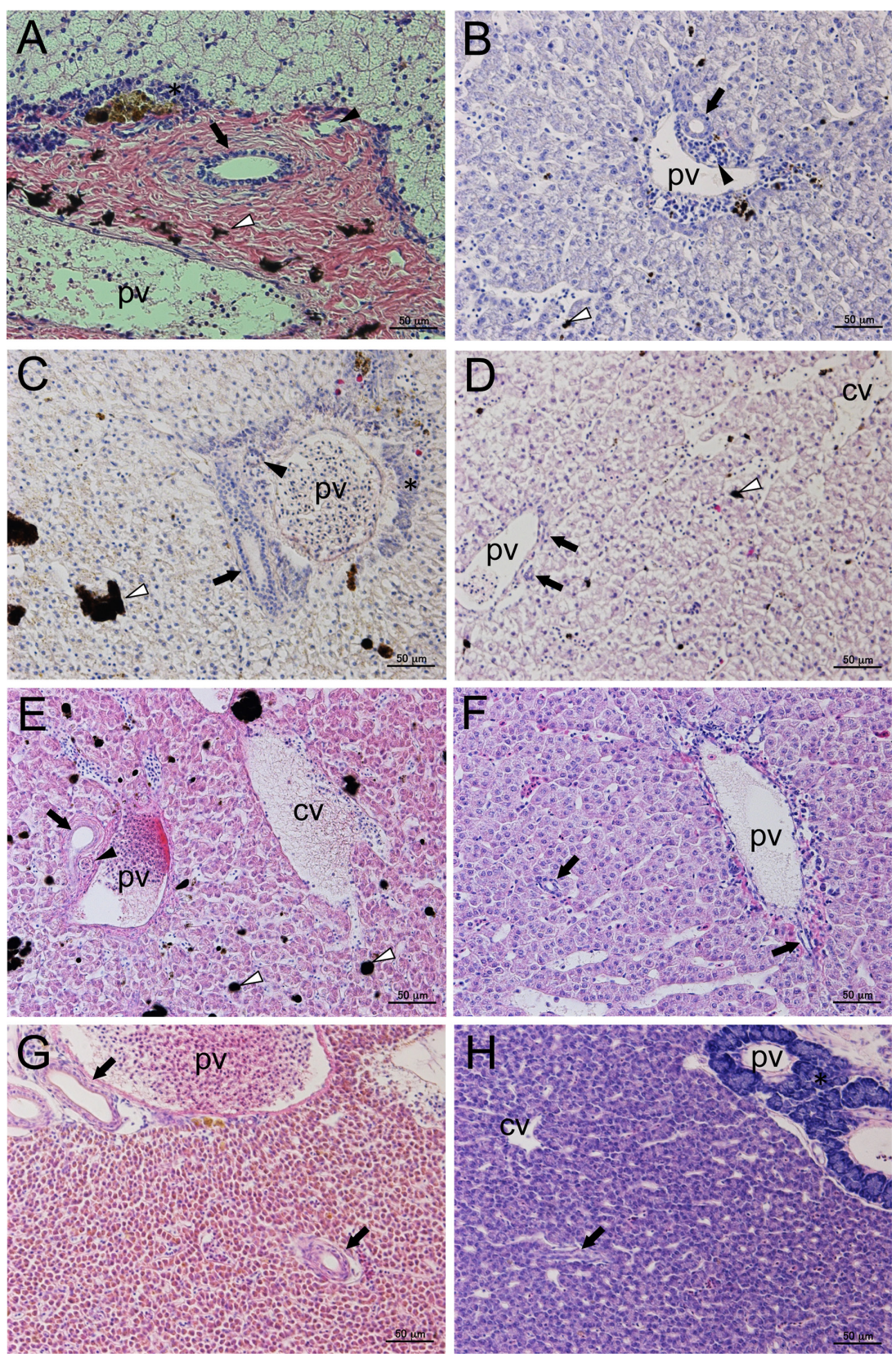

Fig. 6. Intrahepatic bile duct distribution in livers of various Actinopterygii. (A) Bichir. (B) Sterlet. (C) Spotted gar. (D) Bowfin. (E) Silver arowana. (F) Japanese eel. (G) Goldfish. (H) Thread-sail filefish. H-E staining. Intrahepatic bile ducts run along portal veins in the livers of the bichir, sterlet, spotted gar, bowfin, and silver arowana (arrows, A-E). Exocrine tissues of the pancreas are observed around portal vein in the liver of the spotted gar (asterisk, C). In the liver of the Japanese eel, intrahepatic bile ducts are noted around portal veins and in the parenchyma (arrows, F). Bile ducts are located near portal veins in the hilum, but intrahepatic bile ducts are distributed independently of the portal vein configuration in the goldfish (arrows, G). In the filefish liver, intrahepatic bile ducts develop independently of portal vein configuration (H). Portal veins are accompanied by the pancreatic tissue (asterisk). Black arrowheads indicate the hepatic artery. White arrowheads indicate melanomacrophages. cv, central vein; pv, portal vein. 

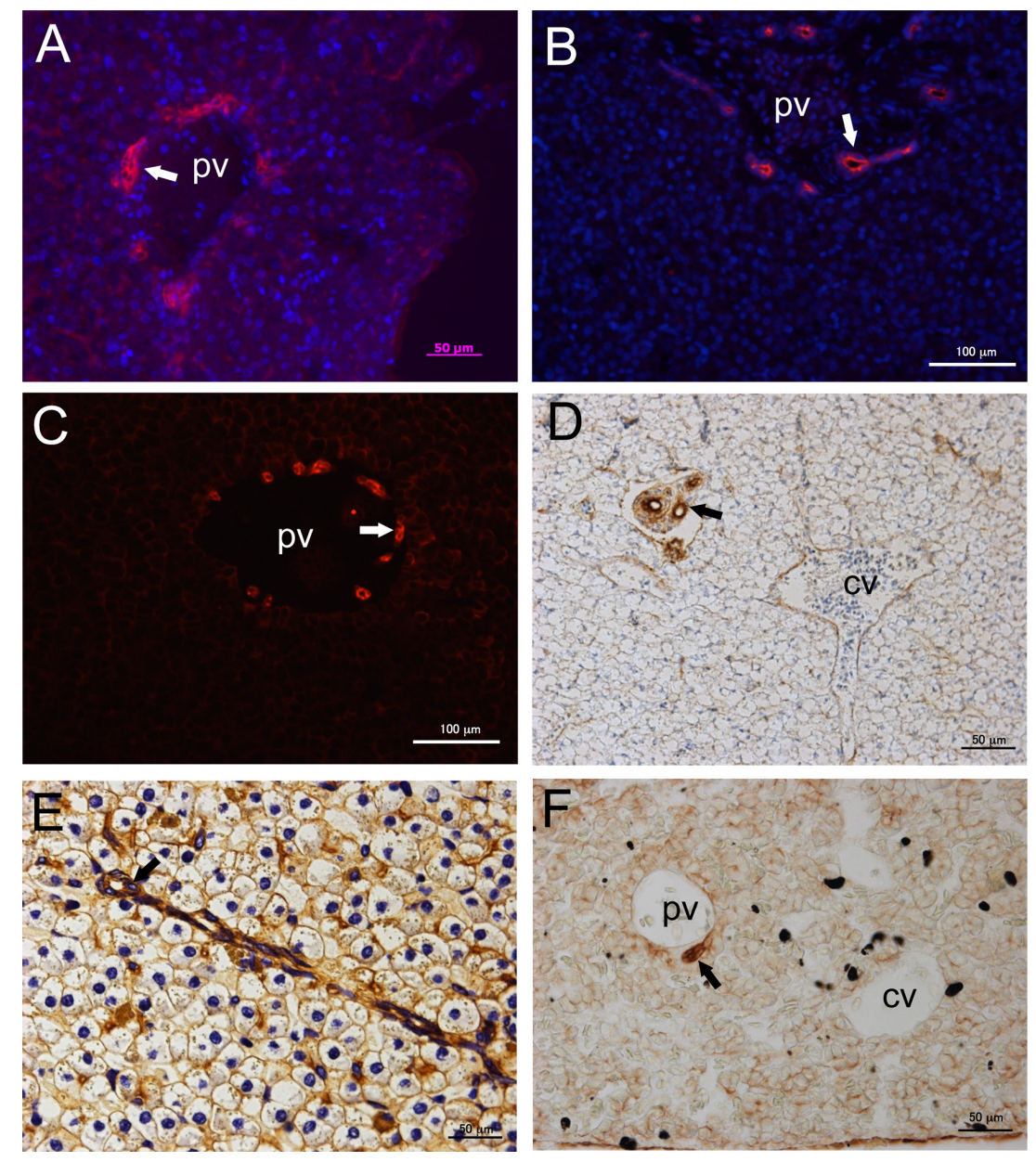

Fig. 7. Cytokeratin immunohistochemistry in various vertebrate livers. (A) Hagfish. (B) Japanese bullhead shark. (C) Bichir. (D) Thread-sail filefish. (E) Marbled lungfish (Protopterus aethiopics). (F) Xenopus tropicalis. The anti-cytokeratin antibody used reacts with biliary epithelial cells and ductular cells around portal veins in the hagfish, bullhead shark, bichir and X. tropicalis livers (A, B, C, F). Bile ducts, which are positive for cytokeratin immunostaining, are developed independently of blood vessels in the livers of the marbled lungfish and filefish (D, E). Arrows indicate bile ducts or bile ductules. cv, central vein; pv, portal vein.

adipose tissue as seen in the coelacanth liver (Fig. 8D). Hematopoiesis occurred under the Glissonian capsule in the frog liver (Fig. 8H). The histological characteristics of the shark and bichir livers, including development of periportal connective tissue, abundant fat accumulation and distribution of melanomacrophages, resembled those of the coelacanth liver.

\section{Discussion}

Portal triad formation in the coelacanth and tetrapod livers

Although the coelacanth liver was not histologically well preserved, the present study demonstrated that it had a mammalian-type hepatic architecture with a portal triad in which intrahepatic bile ducts ran parallel to portal veins, and a hepatic artery was also detectable in portal connective tissues (Fig. 9). The hepatic architecture of the coelacanth highly contrasted with those of the four species of lungfish examined, in which the configurations of the intrahepatic bile ducts and portal veins were independent (Fig. 9). At present, it is unknown why the architecture of the two phylogenetically related sarcopterygians was different. The hepatic architecture of the lungfish rather resembled that of actinopterygian fishes after Elopomorpha in terms of bile duct and ductular distribution in the liver parenchyma, and may be an example of convergent evolution (Fig. 9) ${ }^{4}$. Their ductular development in the liver parenchyma might also be related to oval cell proliferation in injured mammalian livers, in which another pathway for bile transportation possibly works to compensate for abnormal bile canalicular function of hepatocytes $^{10)}$. The ancestors of the lungfish and actinopterygian 

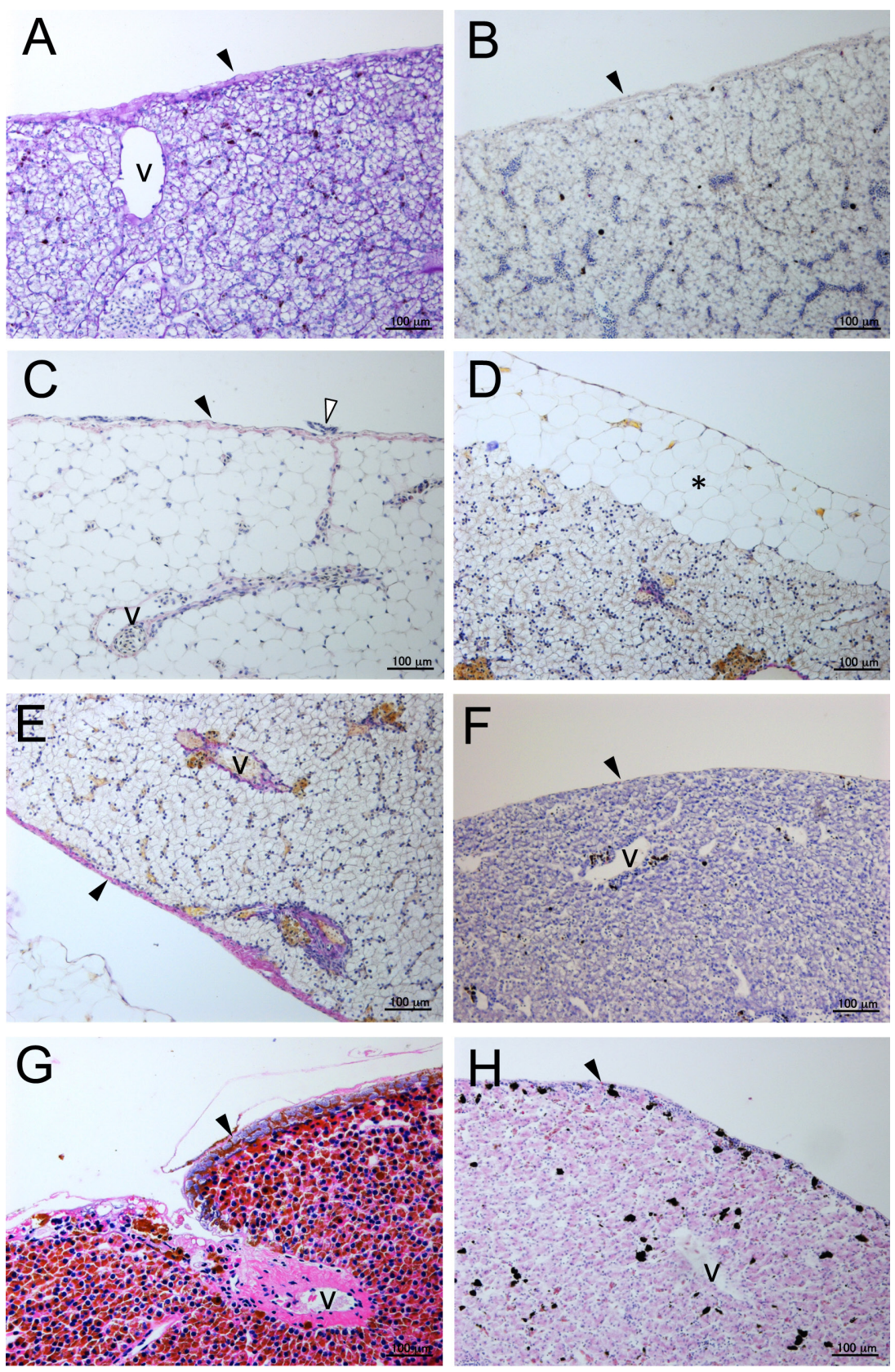

Fig. 8. Heterogeneous capsule tissues of various vertebrate livers. (A) Hagfish. (B) Silver chimaera. (C) Frilled shark. (D, E) Bichir. (F) Starlet. (G) African lungfish (Protopterus annectens). (H) Xenopus tropicalis. PAS-H staining (A). H-E staining (B-H). All livers are covered with various capsule tissues (arrowhead) (A-H). The thickness of the capsule varies among the animals examined. The capsules covering the hagfish, shark, bichir and lungfish livers are thick compared with those of mammalian livers (A-C, E, G). The bichir liver is partially covered with adipose tissue as seen in the coelacanth liver (asterisk in D). Hematopoiesis is observed under the capsule in the frog liver $(\mathrm{H})$. White arrowhead indicates partial thickening of the coelomic epithelium in the frilled shark liver (C). v, vessel.

fishes after Elopomorpha, both of which may have lived in freshwater environments, might have adapted to similar severe environments, which could cause liver injury inducing ductular reaction, with the non-portal triad-type liver architecture ${ }^{4}$. In this regard, it may be of note that the coelacanth survives in the deep sea of specific areas (near the Comoro Islands off the east coast of Africa, and in the waters off Sulawesi, Indonesia), maintaining the portal triad-type hepatic architecture, although its ancestor may have been distributed worldwide in both marine and freshwater environments ${ }^{11,12)}$. Our data on the coelacanth liver also suggest that the prototype for the hepatic archi- 


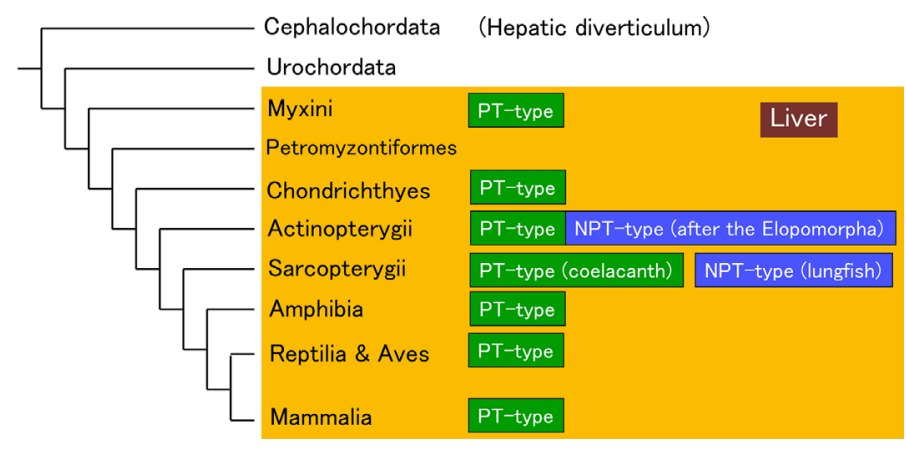

Fig. 9. Phylogenetic tree of vertebrates for the hepatic architecture. The portal triad (PT)-type architecture is developed in many vertebrates, including the hagfish, chondrichthyans, coelacanth and teterapods. In contrast, the lungfish and Teleostei have the non-portal triad (NPT)-type architecture.

tecture with the portal triad may have been generated when the agnathans appeared, and be conserved in tetrapod livers through the evolution of vertebrates (Fig. 9) ${ }^{4,13}$. The ancestors of tetrapods, including extinct species such as the Acanthostega and Ichthyostega, may have had the portal triad-type hepatic architecture. It would be intriguing to study how the lungfish liver differs from amphibian and coelacanth livers in terms of hepatic functions, including bile secretion, as well as hepatic architecture. In the Actinopterygii, the whole genome duplication occurring before the divergence of Osteoglossomorpha might be related to a change in hepatic architecture ${ }^{4,14)}$. Thus, it is important to analyze lungfish liver development from the standpoint of genome duplication of genes involving biliary duct formation, including the Jag1 gene, which codes for one of the bile duct inducers acting on periportal hepatoblasts during mammalian liver development ${ }^{15-17}$.

\section{Histological characteristics of the coelacanth liver}

The coelacanth liver was also remarkably fatty like those of the sharks and bichir in the present study. The fatty liver may be used for buoyancy control with the fatty air bladder, which does not function as a respiratory $\operatorname{organ}^{8)}$. It has recently been reported that a potentially functional, well-developed lung is present at the early embryonic stage of the coelacanth, and that its growth is arrested at later ontogenetic stages, when the lung is vestigial $^{18,19)}$. The present study demonstrated abundant depositions of collagen fibrils or fibers in the thick connective tissue layer of portal veins in the coelacanth liver. Melanomacrophages were also noted. These histological characteristics, in addition to the development of periportal bile ducts, may resemble those of the bichir and shark livers in addition to the development of periportal bile ducts, implying that these species may be phylogenetically related or may have developed similar histological structures of the liver to adapt to their habitats. Furthermore, it may be noteworthy that the adipose tissue partially covered the liver parenchyma with the Glissonian capsule in the coelacanth liver like the bichir liver, suggesting that it may be similar to the bichir liver in histology.

\section{Conclusion}

The coelacanth liver has a mammalian-type hepatic architecture with a portal triad. The ancestors of tetrapod animals may have had a portal triad-type liver architecture. Fresh, intact coelacanth livers will be required for precise examination of the hepatic architecture in the future.

\section{Acknowledgments}

We thank Professor Emeritus Takeo Mizuno of the University of Tokyo and Prof. Nelson Fausto of the University of Washington for their interest in our study and encouragement, and Mr. Kim Barrymore for his help in preparing our manuscript. The authors also thank Dr. T. Koike and Mr. N. Ota for their discussion, and Ms. T. Abo and Mr. H. Kametani for their technical assistance. This work was supported in part by a Grant-in-Aid for Scientific Research (C) from the Japan Society for the Promotion of Science (JSPS) (Grant Number 25440153). The authors declare that there are no conflicts of interest concerning this article.

\section{References}

1) Akiyoshi H, Inoue AM: Comparative histological study of hepatic architecture in the three orders amphibian livers. Comp Hepatol 2012; 11:2.

2) Umezu A, Kametani A, Akai Y, Koike T, Shiojiri N: Histochemical analyses of hepatic architecture of the hagfish with special atten- 
tion to periportal biliary structures. Zool Sci 2012; 29:450-457.

3) Odokuma EI, Omokaro EI: Comparative histologic anatomy of vertebrate liver. Ann Bioanthropol 2015; 8:1-5.

4) Shiojiri N, Kametani H, Ota N, Akai Y, Fukuchi T, Abo T, Tanaka S, Sekiguchi J, Matsubara S, Kawakami H: Phylogenetic analyses of the hepatic architecture in vertebrates. J Anat 2018; 232:200-213.

5) Akiyoshi $\mathrm{H}$, Inoue $\mathrm{A}$ : Comparative histological study of teleost livers in relation to phylogeny. Zool Sci 2002; 21:841-850.

6) Figueiredo-Fernandes AM, Fontaínhas-Fernandes AA, Monteiro RA, Reis-Henriques MA, Rocha E: Spatial relationships of the intrahepatic vascular-biliary tracts and associated pancreatic acini of Nile tilapia, Oreochromis niloticus (Teleostei, Cichlidae): a serial section study by light microscopy. Ann Anat 2007; 189:17-30.

7) Nejedli S, Gajger IT: Hepatopancreas in some sea fish from different species and the structure of the liver in teleost fish, common pandora, Pagellus erythinus (Linnaeus, 1758) and whiting, Merlangius merlangus euxinus (Nordmann, 1840). Vet Arhiv 2013; 83: 441-452.

8) Millot J, Anthony J, Robineau D, Anatomie de latimeria chalumnae. 3. Appareil digestif, appareil respiratoire, appareil urogénital, glandes endocrines, appareil circulatoire, téguments, écailles, conclusions générales. Centre national de la recherche scientifique, Paris, 1978; 22-24.

9) Junqueira LC, Bignolas G, Brentani RR: Picrosirius staining plus polarization microscopy, a specific method for collagen detection in tissue sections. Histochem J 1979; 11:447-455.

10) Nagahama $Y$, Sone $M$, Chen $X$, Okada $Y$, Yamamoto $M$, Xin B, Matsuo Y, Komatsu M, Suzuki A, Enomoto K, Nishikawa Y: Contributions of hepatocytes and bile ductular cells in ductular reactions and remodeling of the biliary system after chronic liver injury. Am J Pathol 2014; 184:3001-3012.
11) Johanson Z, Long JA, Talent JA, Janvier P, Warren JW: Oldest coelacanth, from the Early Devonian of Australia. Biol Lett 2006; 2:443-446.

12) Zhu M, Yu X, Lu J, Qiao T, Zhao W, Jia L: Earliest known coelacanth skull extends the range of anatomically modern coelacanths to the Early Devonian. Nat Commun 2012; 3:772.

13) Ueno $T$, Ishihara A, Yagi $S$, Koike T, Yamauchi K, Shiojiri N: Histochemical analyses on biliary development during metamorphosis of Xenopus laevis tadpoles. Zool Sci 2015; 32:88-96.

14) Meyer A, Van de Peer $Y$ : From $2 R$ to $3 R$ : evidence for a fishspecific genome duplication (FSGD). Bioessays 2005; 27:937-945.

15) Oda T, Elkahloun AG, Pike BL, Okajima K, Krantz ID, Genin A, Piccoli DA, Meltzer PS, Spinner NB, Collins FS, Chandrasekharappa SC: Mutations in the human Jagged1 gene are responsible for Alagille syndrome. Nature Genet 1997; 16:235-242.

16) McCright B, Lozier J, Gridley T: A mouse model of Alagille syndrome: Notch2 as a genetic modifier of Jagl haploinsufficiency. Development 2002; 129:1075-1082.

17) Hofmann JJ, Zovein AC, Koh H, Radtke F, Weinmaster G, IruelaArispe ML: Jagged1 in the portal vein mesenchyme regulates intrahepatic bile duct development: insights into Alagille syndrome. Development 2010; 137:4061-4072.

18) Cupello C, Brito PM, Herbin M, Meunier FJ, Janvier P, Dutel H, Clément G: Allometric growth in the extant coelacanth lung during ontogenetic development. Nat Commun 2015; 6:8222.

19) Cupello C, Meunier FJ, Herbin M, Clément G, Brito PM: Lung anatomy and histology of the extant coelacanth shed light on the loss of air-breathing during deep-water adaptation in actinistians. R Soc Open Sci 2017; 4:161030. 